\title{
Challenges in the diagnosis and management of autoimmune hepatitis
}

\author{
Albert J Czaja MD
}

\begin{abstract}
AJ Czaja. Challenges in the diagnosis and management of autoimmune hepatitis. Can J Gastroenterol 2013;27(9):531-539.
\end{abstract}

BACKGROUND: Autoimmune hepatitis has diverse clinical phenotypes and outcomes that challenge current diagnostic criteria and management algorithms.

OBJECTIVES: To highlight the major difficulties in diagnosis and management, describe the efforts to ease them and encourage further progress in problem solving.

METHODS: The MEDLINE database was reviewed for published experiences from 1984 to 2013.

RESULTS: Acute or acute severe (fulminant) hepatitis, asymptomatic mild disease, and histological findings of centrilobular necrosis or bile duct injury can confound diagnosis and treatment. Continuation of conventional therapy until normal liver test results and liver tissue reduces the frequency of relapse, but does not prevent its occurrence. Problematic patients can be identified using mathematical models, clinical phenotype, serological markers and the speed of improvement after treatment; however, their recognition and treatment are inconsistent. Mycophenolate mofetil can rescue patients with azathioprine intolerance but is less effective for refractory disease. Budesonide in combination with azathioprine can be used frontline, but is effective primarily in noncirrhotic, uncomplicated disease. Molecular and cellular interventions are feasible but largely unevaluated.

DISCUSSION: Resolution of the current challenges requires revision of diagnostic criteria, characterization of biological markers that reflect pathogenic pathways, development of dynamic indexes based on changes in disease behaviour, and introduction of new pharmacological, molecular and cellular interventions that have undergone rigorous evaluation.

CONCLUSION: These challenges reflect important remediable deficiencies in current management.

Key Words: Autoimmune; Challenges; Interventions; Nonstandard drugs; Phenotypes

\section{Les problèmes dans le diagnostic et la prise en charge de l'hépatite auto-immune}

HISTORIQUE : L'hépatite auto-immune s'associe à des phénotypes cliniques et des issues variés qui remettent en question les critères diagnostiques et les algorithmes de prise en charge actuels.

OBJECTIFS : Faire ressortir les principaux problèmes de diagnostic et de prise en charge, décrire les efforts pour les atténuer et favoriser de nouveaux progrès dans la résolution de problèmes.

MÉTHODOLOGIE : Le chercheur a analysé la base de données MEDLINE pour obtenir les expériences publiées entre 1984 et 2013.

RÉSULTATS : L'hépatite aiguë ou aiguë sévère (fulminante), la maladie bénigne asymptomatique et les observations histologiques de la nécrose centrolobulaire ou d'une atteinte du canal cholédoque peuvent avoir une influence confusionnelle sur le diagnostic et le traitement. Le maintien du traitement classique jusqu'à l'obtention de tests hépatiques et de tissus hépatiques normaux réduit la fréquence des récidives, mais n'en prévient pas l'occurrence. On peut déceler les patients problématiques au moyen de modèles mathématiques, d'un phénotype clinique, de marqueurs sérologiques et de la vitesse d'amélioration après le traitement. Cependant, leur dépistage et leur traitement ne sont pas constants. Le mofétil de mycophénolate peut aider les patients présentant une intolérance à l'azathioprine, mais est moins efficace en cas de maladie réfractaire. Le budésonide associé à l'azathioprine peut être utilisé en première ligne, mais est surtout efficace en cas de maladie non cirrhotique et non complexe. Les interventions moléculaires et cellulaires sont faisables, mais largement sous-évaluées.

EXPOSÉ : Pour résoudre les problèmes actuels, il faut revoir les critères diagnostiques, la caractérisation des marqueurs biologiques qui reflètent les voies pathogènes, l'élaboration d'indices dynamiques fondés sur l'évolution du comportement de la maladie et l'adoption de nouvelles interventions pharmacologiques, moléculaires et cellulaires qui ont subi une évaluation rigoureuse.

CONCLUSION : Ces problèmes reflètent d'importantes lacunes de prise en charge qui peuvent être corrigées.

expanding and the conventional therapies are being individualized according to particular phenotypic characteristics and treatment responses $(7,8)$. Advances in the understanding of critical pathogenic pathways (9-11) and experiences in other immune-mediated diseases have identified opportunities to evaluate molecular and cellular interventions that promise to transform current management strategies and further diversify and individualize treatment options $(3,12-15)$. The goals of the present review are to indicate the current challenges, describe the efforts to meet them, and encourage further progress in the diagnosis and management of this complex disease.

\section{UNDERSTANDING THE DIVERSITY OF CLINICAL PHENOTYPES AT PRESENTATION}

Autoimmune hepatitis may have an acute or acute severe (fulminant) presentation that challenges the diagnosis by resembling an acute viral or toxic hepatitis (16). It may have an asymptomatic presentation that challenges the need for treatment $(17,18)$, and it may have histological findings of centrilobular (zone 3) necrosis (19-23) or bile duct not sustainable because the clinical spectrum of the disease is

Division of Gastroenterology and Hepatology, Mayo Clinic College of Medicine, Rochester, Minnesota, USA

Correspondence: Dr Albert J Czaja, Mayo Clinic College of Medicine, 200 First Street Southwest, Rochester, Minnesota 55905, USA.

Telephone 507-284-8118, fax 507-284-0538, e-mail czaja.albert@mayo.edu

Received for publiction March 31, 2013. Accepted May 12, 2013 
TABLE 1

Diversity of clinical phenotypes at presentation

\begin{tabular}{|c|c|c|}
\hline Phenotype at presentation & Features & Challenges \\
\hline \multirow{5}{*}{$\begin{array}{l}\text { Acute onset or acute severe } \\
\text { (fulminant) presentation }\end{array}$} & Abrupt onset at discovery, $25 \%$ to $75 \%(16,28)$ & Resembles acute viral or toxic hepatitis (16) \\
\hline & Encephalopathy $\leq 26$ weeks, $6 \%(16,29)$ & Absent classical clinical and laboratory features $(31,33,34)$ \\
\hline & ANA absent or weak, $29 \%$ to $39 \%(31,33,34)$ & Nonclassical histological findings $(29,32)$ \\
\hline & IgG normal, $25 \%$ to $39 \%(31,33,34)$ & Corticosteroid treatment versus LT $(36,42)$ \\
\hline & Centrilobular necrosis, $86 \%(20,29,32,35)$ & \\
\hline
\end{tabular}

Low diagnostic scores (31)

Corticosteroid response, $36 \%$ to $100 \%$ (36)

Five-year survival rate after LT, $78 \%$ to $80 \%(40,41)$

Asymptomatic presentation

Frequency, $25 \%$ to $34 \%(17,18)$

Possible 10-year survival untreated (18)

Moderate-severe lobular hepatitis, 91\% (17)

Periportal and bridging fibrosis, $41 \%$ (17)

Resolution untreated, $12 \%$ (43)

Late symptoms, $26 \%$ to $70 \%(17,18)$

Untreated 10-year survival, 67\% (43)

Centrilobular (zone 3) necrosis Frequency, 29\% (23)

Interface hepatitis present, 78\% (20)

Occurs in acute and chronic disease (23)

Bile duct injury

Nondestructive cholangitis, $7 \%$ to $9 \%(44,46)$

Destructive cholangitis, $\leq 5 \%(44,46)$

Isolated transient findings possible (24)

Overlap syndrome if cholestasis $(45,47)$

\author{
Uncertain need for treatment $(18,43)$ \\ Treatment risks, 14\% (43) \\ Fluctuating disease severity and progression $(17,43)$ \\ Late symptoms $(17,18)$ \\ Immediate versus late treatment $(17,43)$
}

Diagnostic confusion $(16,23)$

Resembles acute toxic, ischemic or drug-induced liver injury $(16,29)$

Distinguishing PBC, PSC or overlap syndrome (47)

Treatment strategy (corticosteroids alone or with ursodeoxycholic acid) (47)

Numbers in parentheses refer to references. ANA Antinuclear antibodies; IgG Immunoglobulin G; LT Liver transplantation; PBC Primary biliary cirrhosis; PSC Primary sclerosing cholangitis

injury $(24,25)$ that challenge diagnostic dogma. These atypical phenotypes at presentation are outside the domains of current criteria for the disease $(26,27)$; however, they must be recognized to ensure timely intervention.

Acute and acute severe (fulminant) presentations

Autoimmune hepatitis may have an acute onset, defined as an abrupt occurrence of symptoms and laboratory abnormalities coincident with disease discovery, in $25 \%$ to $75 \%$ of patients $(16,28)$. It may also have an acute severe (fulminant) presentation, defined as hepatic encephalopathy within 26 weeks of disease discovery with or without cirrhosis, in $6 \%$ of patients $(16,29)$ (Table 1$)$. The acute onset may be due to an unsuspected chronic disease that has exacerbated spontaneously, newly formed severe disease, chronic disease with superimposed acute injury ('acute-on-chronic disease') or disease that has developed as an aftermath of liver transplantation $(16,30)$.

The acuteness of the presentation may contribute to its variance from the classical phenotype of autoimmune hepatitis (Table 1). The serum immunoglobulin $G$ level is normal in $25 \%$ to $39 \%$ of patients with acute and acute severe (fulminant) presentations; antinuclear antibodies are absent or weakly demonstrated in $29 \%$ to $39 \%$; and serum $\gamma$-globulin levels and diagnostic scores by the international scoring system are lower than in classical chronic presentations (16,3134). Centrilobular zone 3 necrosis, submassive hepatic necrosis or massive hepatic necrosis occur in $86 \%$ of patients with acute and acute severe (fulminant) autoimmune hepatitis (34), and the presence of interface hepatitis in most patients with centrilobular necrosis (20), especially in conjunction with plasmacytic infiltration or hepatocyte rosettes $(32,35)$, typifies the histological features of acute-onset disease. Massive hepatic necrosis, centrilobular hemorrhagic necrosis with lymphoplasmacytic infiltration, lymphoid aggregates and plasma cell infiltration typify the histological features of acute severe (fulminant) autoimmune hepatitis (29).

Corticosteroid therapy is effective in $36 \%$ to $100 \%$ of individuals with acute or acute severe (fulminant) autoimmune hepatitis depending, in part, on the timeliness of diagnosis and treatment (36). Mortality has uniformly followed in these patients if there has been no improvement within two weeks of corticosteroid treatment, and they should be considered for liver transplantation (37). Oral prednisolone achieves a faster peak plasma concentration than oral prednisone (mean $[ \pm \mathrm{SD}] 1.3 \pm 0.7 \mathrm{~h}$ versus $2.6 \pm 1.3 \mathrm{~h}$ ), is not dependent on hepatic conversion to the active metabolite and has a systemic availability of $99 \pm 8 \%$ (compared with $84 \pm 13 \%$ for oral prednisone) $(38,39$ ) . These attributes support a preference for prednisolone in the treatment of acute severe (fulminant) autoimmune hepatitis. Liver transplantation for acute liver failure in autoimmune hepatitis has a five-year survival rate of $78 \%$ to $80 \%(40,41)$ and the procedure should not be delayed in suitable candidates $(36,42)$.

\section{Asymptomatic autoimmune hepatitis}

Autoimmune hepatitis may have an asymptomatic presentation in $25 \%$ to $34 \%$ of patients $(17,18)$; the 10 -year survival rate of untreated patients with this presentation may exceed $80 \%$ (18) (Table 1). This favourable outcome must be counterbalanced against its uncertainty and the risk of progressive liver disease. The frequencies of moderatesevere lobular hepatitis ( $91 \%$ versus $95 \%$ ), periportal fibrosis $(41 \%$ versus $39 \%$ ) and bridging fibrosis (41\% versus $48 \%$ ) are similar in asymptomatic and symptomatic patients; $26 \%$ to $70 \%$ of asymptomatic patients become symptomatic $(17,18)$. Furthermore, untreated asymptomatic patients improve less frequently than treated symptomatic patients with severe disease $(12 \%$ versus $63 \%)$ and they have a lower 10 -year survival rate (67\% versus 98\%) (43). The asymptomatic state at presentation does not preclude the need for treatment; the challenge is to develop an individualized management strategy that minimizes disease progression. The uncertainty that mild disease remains mild must guide the treatment decision; this uncertainty favours the treatment of all patients regardless of symptom status or disease severity at presentation (43).

Centrilobular necrosis and bile duct injury

Autoimmune hepatitis may have histological features of centrilobular (zone 3$)$ necrosis $(22,23)$ or bile duct injury $(24,25,44,45)$; these findings challenge the classical pathological concepts of the disease (Table 1). Centrilobular necrosis is present in $29 \%$ of patients with 
TABLE 2

Recommended adjustments in current treatment strategies

\begin{tabular}{|c|c|c|}
\hline Treatment adjustments & Regimens & Challenges \\
\hline $\begin{array}{l}\text { Treatment until normal liver } \\
\text { tests and liver tissue }\end{array}$ & $\begin{array}{l}\text { Continue conventional treatment until serum AST, ALT, y-globulin and IgG levels } \\
\text { normal }(49,60)\end{array}$ & $\begin{array}{l}\text { Preventing and treating drug intolerances }(8,49) \\
\text { Justifying liver biopsy before drug withdrawal }(8)\end{array}$ \\
\hline & $\begin{array}{l}\text { Maintain normal liver tests on treatment for three to eight months before liver } \\
\text { biopsy (8) }\end{array}$ & $\begin{array}{l}\text { Indefinite treatment possible }(63) \\
\text { Relapse, } \geq 20 \%(60,63,68)\end{array}$ \\
\hline
\end{tabular}

Normal liver tissue or inactive cirrhosis required before drug withdrawal $(8,49)$

Discontinue prednisone alone or with azathioprine over six-week period (8)

Monitor serum AST, ALT, y-globulin levels every three weeks for three months, every

three to six months for one year, then every six to 12 months thereafter $(8,49)$

Increase in serum AST or ALT level >3-fold ULN or y-globulin level >2 g/dL

indicates relapse (63)

Long-term maintenance Restart original treatment until laboratory resolution $(62,64)$

therapy after relapse Increase azathioprine dose to $2 \mathrm{mg} / \mathrm{kg}$ as prednisone withdrawn $(62,64)$

Continue azathioprine at fixed dose $(62,64)$

Use low-dose prednisone $\leq 10 \mathrm{mg}$ daily if azathioprine intolerant $(65,66)$ Azathioprine intolerance $(64)$
Breakthrough exacerbation (64)
Oncogenic and teratogenic risks $(64,82)$
Long-term corticosteroid treatment if azathioprine
intolerance $(65,66)$

Numbers in parentheses refer to references. ALT Alanine aminotransferase; AST Aspartate aminotransferase; Ig Immunoglobulin; ULN Upper limit of normal range

autoimmune hepatitis regardless of the acuteness of the presentation, or the presence or absence of cirrhosis (23). Classical interface hepatitis is found in $78 \%$ of patients with centrilobular necrosis (20); this mixed histological pattern suggests a transition state between acute and chronic liver injury, an acute exacerbation of pre-existent chronic disease or an acute-on-chronic process (16). Sequential liver tissue examinations in patients with centrilobular necrosis have demonstrated spontaneous transformation from this pattern to that of classical interface hepatitis (20). This evolutionary sequence suggests that the centrilobular pattern is an acute early stage liver injury in patients without hepatic fibrosis and an acute superimposed liver injury in patients with hepatic fibrosis. Centrilobular necrosis is a dynamic histological pattern in autoimmune hepatitis, and does not implicate an etiological factor, characterize a particular clinical phenotype, or compel an alternative diagnosis or treatment (23).

Nondestructive lymphocytic or pleomorphic cholangitis is present in $7 \%$ to $9 \%$ of patients with classical autoimmune hepatitis (44), and fibrous cholangitis (44) or destructive cholangitis (florid duct lesion) $(24,46)$ can be present in $\leq 5 \%$ (Table 1 ). Histological features of bile duct injury are outside the canon of autoimmune hepatitis (26); however, the occurrence of these coincidental background histological changes in the absence of clinical cholestasis does not detract from the diagnosis of autoimmune hepatitis or preclude conventional treatment (24). Concurrent findings of inflammatory bowel disease, an increased serum alkaline phosphatase level $>2$-fold the upper limit of the normal range, serum $\gamma$-glutamyl transferase level $\geq 5$-fold the upper limit of the normal range, or numerous florid duct lesions on histological examination compel the performance of additional tests that include determination of serum antimitochondrial antibodies and endoscopic or magnetic resonance cholangiography (47). These studies may indicate that primary biliary cirrhosis (PBC), primary sclerosing cholangitis, or an overlap syndrome between autoimmune hepatitis and $\mathrm{PBC}$ or primary sclerosing cholangitis is the most appropriate diagnosis $(47,48)$.

\section{IMPROVING CURRENT TREATMENT REGIMENS}

Prednisone (or prednisolone) alone $(60 \mathrm{mg} /$ day tapered each week to $20 \mathrm{mg} /$ day over a four-week period) or a lower dose $(30 \mathrm{mg} /$ day tapered each week to $10 \mathrm{mg} /$ day over a four-week period) in combination with azathioprine ( $50 \mathrm{mg} / \mathrm{day}$, or $1 \mathrm{mg} / \mathrm{kg} /$ day to $2 \mathrm{mg} / \mathrm{kg} /$ day) is the standard treatment of autoimmune hepatitis (49). Treatment improves liver tests and liver tissue to normal or near normal in most patients within 24 months $(50,51)$, prevents progressive hepatic fibrosis $(52)$ and extends 10 -year survival to $74 \%$ to $89 \%(53-57)$. The major management challenges are to achieve an optimal end point of therapy and to manage relapse after corticosteroid withdrawal.
Optimal end point of conventional corticosteroid therapy

Corticosteroid treatment should be continued until normalization of liver tests and liver tissue (Table 2) (49). Patients who sustain remission after corticosteroid withdrawal have significantly lower serum aspartate aminotransferase (AST), $\gamma$-globulin and immunoglobulin G levels immediately before histological examination and drug withdrawal than those who relapse (58-60). Liver tissue examination is best performed after normal laboratory tests have been maintained on treatment for three to eight months $(7,8)$. Laboratory improvement lags behind histological resolution, and a protracted interval of continued treatment beyond test resolution increases the frequency of documenting histological resolution $(8,61)$.

Histological examination is necessary to accurately classify the treatment response and direct the next action (8). Patients with incomplete histological resolution who exacerbate after treatment have been prematurely withdrawn from medication, and they should be retreated with conventional corticosteroid therapy until an optimal end point is achieved (62). Patients with complete histological resolution who exacerbate after drug withdrawal have relapsed (63), and they are candidates for long-term (indefinite) maintenance therapy with azathioprine $(2 \mathrm{mg} / \mathrm{kg} /$ day $)(7,8,49,62,64)$ or low-dose prednisone $(\leq 10 \mathrm{mg} /$ day $)(8,65,66)$. The decision not to proceed with liver tissue examination reflects a willingness to manage responses empirically outside of guidelines (49) or a commitment to maintaining therapy indefinitely without expectation of drug withdrawal (67).

\section{Management of relapse}

Treatment until normal liver tests and liver tissue reduces the frequency of relapse after drug withdrawal but does not eliminate its occurrence (60). Patients treated to normal liver tests and liver tissue exhibit a frequency of relapse that is lower than that of patients treated to near-normal liver tests and liver tissue (20\% to $40 \%$ versus $50 \%$ to $87 \%)$; however, they remain at risk for relapse and disease progression $(60,63,68)$. Repeated relapses and retreatments are associated with progressive increases in the cumulative frequencies of cirrhosis $(38 \%$ versus $4 \%$ ) and requirement for liver transplantation or death from hepatic failure (20\% versus $0 \%$ ) compared with patients who sustain their remission after treatment (69). The challenge is to avoid the consequences of repeated exacerbations and retreatments; the institution of indefinite maintenance therapy after the first relapse meets this challenge (Table 2).

The preferred strategy after relapse is to start therapy with azathioprine $(2 \mathrm{mg} / \mathrm{kg} /$ day $)$ and to continue this treatment indefinitely $(7,8,49,62,64)$. Conventional corticosteroid therapy is restarted after relapse to normalize the laboratory tests, then the corticosteroid 
TABLE 3

Predictive prognostic features of autoimmune hepatitis (AlH)

\begin{tabular}{|c|c|c|}
\hline Prognostic features & Implications & Challenges \\
\hline Model scores & $\begin{array}{l}\text { MELD score } \geq 12 \text { points predicts treatment failure (sensitivity, } \\
\text { 97\%; specificity, 68\%) (70) } \\
\text { Unimproved UKELD predicts poor outcome (sensitivity, 85\%; } \\
\text { specificity, } 68 \% \text { ) (71) }\end{array}$ & $\begin{array}{l}\text { Not disease-specific }(70,71) \\
\text { Low specificities for treatment failure }(70,71)\end{array}$ \\
\hline Clinical phenotype & $\begin{array}{l}\text { Young adults have HLA DRB1*03 more frequently than elderly } \\
\text { patients ( } 58 \% \text { versus } 23 \%)(72) \\
\text { Young adults often fail treatment }(33 \%)(72) \\
\text { Elderly patients have cirrhosis (33\%), HLA DRB } 1 * 04(47 \%) \text { and } \\
\text { good response to therapy }(72)\end{array}$ & $\begin{array}{l}\text { Lacks specificity }(72) \\
\text { 'Blunt' prognostic tool }(72) \\
\text { Routine HLA determinations discouraged }(7,8,49)\end{array}$ \\
\hline Serological markers & $\begin{array}{l}\text { Anti-SLA and relapse, } 53 \% \text { to } 100 \%(76,77) \\
\text { Anti-SLA and HLA DRB1*03, } 83 \%(76,78) \\
\text { Anti-SLA sensitivity for AIH, } 7 \% \text { to } 19 \%(79) \\
\text { Anti-SLA specificity for } \mathrm{AlH},>90 \%(77,79) \\
\text { Anti-actin and a-actinin occur with clinical and histological activity, } \\
91 \%(81)\end{array}$ & $\begin{array}{l}\text { Anti-SLA infrequent in AlH }(79) \\
\text { Anti-SLA vary by genotype }(76,79) \\
\text { Absent anti-SLA not predictive }(76) \\
\text { Need indices based on pathogenic pathways (cytokine } \\
\text { levels, immune cell populations) (9) }\end{array}$ \\
\hline Rapidity of treatment response & $\begin{array}{l}\text { Failure to improve within } 2 \text { weeks indicates high mortality }(37,71) \\
\text { Improvement within } 12 \text { months has less cirrhosis }(18 \%) \text { and need } \\
\text { for liver transplantation ( } 2 \%)(51) \\
\text { Elderly respond more quickly than young (51) }\end{array}$ & $\begin{array}{l}\text { Requires time investment to assess response }(37,51,71) \\
\text { No pretreatment predictors }(8) \\
\text { Need dynamic indexes at each stage of disease }(8,37)\end{array}$ \\
\hline
\end{tabular}

Numbers in parentheses refer to references. HLA Human leukocyte antigen; MELD Model of End-stage Liver Disease; SLA Soluble liver antigen; UKELD United Kingdom Model for End-stage Liver Disease

component is withdrawn as the dose of azathioprine is increased to its weight-based level. Clinical and laboratory resolution is maintained in $83 \%$ of patients observed for 12 to 128 months (median 67 months), and the 10 -year probability of a sustained clinical remission is $80 \%$ $(8,64)$. Histological examinations disclose no or minimal inflammatory activity in $94 \%$ of patients; corticosteroid-induced side effects typically improve; and azathioprine is usually well tolerated (64). Arthralgias associated with corticosteroid withdrawal occur in $63 \%$; lymphopenia develops in $8 \%$; myelosuppression occurs in $7 \%$; and diverse malignancies that reflect uncertain risk factors develop in $8 \%$ $(8,64)$.

The long-term administration of low-dose prednisone (or prednisolone) is an alternative management strategy for patients with severe cytopenia or intolerance of azathioprine (65) (Table 2). Conventional corticosteroid therapy is restarted after relapse until clinical and laboratory resolution is achieved. The dose of prednisone (or prednisolone) is then reduced each month by $2.5 \mathrm{mg}$ until instability in serum AST level is recognized. The corticosteroid dose is then increased by $2.5 \mathrm{mg}$ to again stabilize the tests, and the new dose is maintained indefinitely (65). Eighty-seven per cent of patients can be managed on $\leq 10 \mathrm{mg} /$ day of prednisone (median dose $7.5 \mathrm{mg} /$ day); side effects associated with the original corticosteroid regimen improve or disappear in $85 \%$; and new drug-related complications do not develop (65). Lowdose corticosteroid therapy has been maintained safely and successfully for seven to 43 years (median 13.5 years) (66). Low-dose corticosteroid therapy is not designed to induce histological resolution and the possibility of slow histological progression cannot be excluded.

\section{IDENTIFYING PROBLEMATIC PATIENTS EARLY}

The early identification of problematic patients is an ongoing management challenge, and mathematical models $(70,71)$, clinical phenotype at presentation $(72)$, serological markers $(73,74)$ and responsiveness to treatment (51) have been used for this purpose with varying success (Table 3). The objectives have been to recognize individuals whose autoimmune hepatitis will worsen during conventional corticosteroid therapy and to allow early intervention with individualized salvage therapies. Dynamic indexes that assess changes in the tempo of the disease during treatment are emerging as important prognostic instruments in this effort $(37,71)$.
Mathematical models at presentation

Patients who will fail treatment, die of liver failure or require liver transplantation can be identified at presentation by the Model for End-stage Liver Disease (MELD) $(8,70)$ (Table 3). A MELD score of $\geq 12$ points at presentation has a sensitivity of $97 \%$ and specificity of $68 \%$ for treatment failure $(8,70)$. The King's College group has extended these observations by indicating that changes in the MELD score, MELD plus sodium score and the United Kingdom Model for End-stage Liver Disease (UKELD) score during conventional corticosteroid treatment is predictive of outcome in treatment-naive, jaundiced individuals with autoimmune hepatitis (71). Failure of the UKELD score to decrease by at least two points within seven days of treatment has a sensitivity of $85 \%$ and specificity of $68 \%$ for death from hepatic failure, need for emergency transplantation or requirement for second-line immunosuppressive medication (71).

\section{Clinical phenotype at presentation}

The clinical phenotype at presentation can also identify potentially problematic patients (Table 3 ). Individuals who are $\leq 30$ years of age fail conventional corticosteroid therapy more frequently than individuals $\geq 60$ years of age ( $24 \%$ versus $5 \%$ ), and they harbour the human leukocyte antigen (HLA) DRB1*03 more often ( $58 \%$ versus $23 \%$ ) (72). In contrast, individuals who are $\geq 60$ years of age have cirrhosis more commonly at presentation (33\% versus $10 \%$ ), fail conventional corticosteroid treatment less frequently with increasing age and harbour HLA DRB1*04 more often (47\% versus $13 \%$ ) (72).

Treatment failure is uncommon in patients with HLA DRB1*04, possibly because the HLA DRB1*04 alleles encode antigen-binding grooves within the class II molecules of the major histocompatibility complex that accommodate self-antigens that trigger less vigorous immune responses (10). Alternatively, aging decreases the expression of HLA class II molecules and the activation of antigen-stimulated T cells (72); this 'immunosenescence' may favour the development of less severe disease in elderly patients that can progress indolently to cirrhosis and respond well to corticosteroids $(10,72)$.

The clinical phenotype is a 'blunt' prognostic instrument, and it is mainly useful as an alert to possible management difficulties in young adult patients. An awareness of age-related distinctions in disease behaviour and treatment response can direct adjustments in monitoring schedules that accommodate these differences. The challenge is to 
TABLE 4

Promising nonstandard drugs in autoimmune hepatitis (AlH)

\begin{tabular}{|c|c|c|}
\hline Nonstandard drug & Drug attributes & Challenges \\
\hline \multirow[t]{6}{*}{ Mycophenolate mofetil } & Purine antagonist $(62,82)$ & Unlicensed for use in $\mathrm{AlH}(12,82)$ \\
\hline & TPMT independence $(15,82)$ & Expensive (6 to 7 times greater than azathioprine) $(12,82)$ \\
\hline & Response (overall), 45\% $(8,15)$ & Side effects, $3 \%$ to $34 \%(82)$ \\
\hline & Response (AZP intolerance), 58\% $(8,15)$ & Category D drug (teratogenicity) (83) \\
\hline & Response (refractory disease), 23\% $(8,15)$ & Limited target population $(8,82)$ \\
\hline & Corticosteroid sparing, $40 \%(8,15)$ & \\
\hline \multirow[t]{8}{*}{ Budesonide } & Next-generation glucocorticoid $(8,39,62)$ & Uncertain durability of response (84) \\
\hline & Hepatic first-pass clearance $\geq 90 \%$ (39) & Unknown histological response (84) \\
\hline & Metabolites devoid of toxicity (39) & Unexplained low frequency of resolution $(18 \%)$ and high frequency of \\
\hline & Large trial comparing budesonide and AZP with prednisone & side effects (53\%) with standard therapy (84) \\
\hline & and AZP after six months (84) & Ineffective in steroid-refractory or steroid-dependent disease (85) \\
\hline & Laboratory resolution more common ( $47 \%$ versus $18 \%)$ and & Concurrent immune-mediated diseases may flare (85) \\
\hline & side effects fewer ( $28 \%$ versus $53 \%$ ) than standard therapy & Side effects in cirrhosis (86) \\
\hline & $(84)$ & Limited target population $(8,15,39)$ \\
\hline
\end{tabular}

Numbers in parentheses refer to references. AZP Azathioprine; TPMT Thiopurine methyltransferase

develop prognostic instruments that are superior to age and HLA phenotype in predicting outcomes (75).

\section{Serological markers at presentation}

The characterization of serological markers that have prognostic value is an ongoing challenge, and antibodies to soluble liver antigen (antiSLA) and antibodies to actin and $\alpha$-actinin are examples of the investigational effort to meet this challenge (73) (Table 3). Anti-SLA are present in $53 \%$ to $100 \%$ of patients who relapse after corticosteroid withdrawal $(76,77)$, and $83 \%$ of patients with these antibodies harbour HLA DRB1*0301 (76,78). These associations suggest that antiSLA may be surrogate markers of a genetic propensity for severe disease and long-term dependence on continuous corticosteroid therapy. Antibodies to SLA have high specificity for autoimmune hepatitis (>90\%), but they occur in only $7 \%$ to $19 \%$ of patients with the disease $(74,77,79)$. These antibodies illustrate the principal problem with current prognostic markers in that they are informative only when they are present.

Alpha $(\alpha)$ actinin is an immune-reactive region within filamentous $(F)$ actin $(80,81) . F$ actin, in association with its $\alpha$-actinin component, influences cell movement, survival and regeneration $(80,81)$ and may, thereby, affect disease severity. Antibodies to $\alpha$-actinin have a greater sensitivity (44\% versus 19\%), albeit lower specificity ( $84 \%$ versus $>90 \%$ ), for autoimmune hepatitis than anti-SLA, and they have a prognostic implication when they coexist with antibodies to $\mathrm{F}$ actin (anti-actin) (81). Untreated patients with antibodies to both actin and $\alpha$-actinin exhibit clinical ( $91 \%$ versus $52 \%$ ) and histological activity (91\% versus 50\%) more frequently and higher serum AST levels at presentation $(328 \pm 760 \mathrm{U} / \mathrm{L}$ versus $125 \pm 219 \mathrm{U} / \mathrm{L})$ than untreated patients without these antibodies (81) (Table 3).

The dual reactivities to actin and $\alpha$-actinin have not yet been correlated with outcomes, but the low occurrence of both antibodies in autoimmune hepatitis (28\%) suggests that their prognostic value will be limited unless their predictability is near-absolute (81). Direct assessments of the critical cytokine pathways that modulate antibodydependent and cell-mediated mechanisms of liver cell injury and determinations of the number and function of immune cell populations that counter-regulate the autoreactive response may prove closer to the objective of identifying a useful prognostic instrument than the characterization of new antibodies (9).

\section{Rapidity of treatment response}

The rapidity of the response to conventional corticosteroid therapy can also identify problematic patients early (Table 3 ). Patients who have died within four months after presentation have been characterized by the presence of multilobular necrosis on histological examination and the inability to normalize or prevent worsening of at least one liver test abnormality within two weeks of corticosteroid treatment (37). Similarly, $85 \%$ of icteric patients with severe autoimmune hepatitis whose UKELD score does not improve by two points within seven days of corticosteroid treatment experience a poor outcome (71).

Problematic patients with less severe presentations can also be identified by the speed and degree of their improvement during treatment (51) (Table 3). Patients who improve to normal or near-normal liver tests and liver tissue within 12 months of conventional corticosteroid treatment exhibit a lower frequency of progression to cirrhosis (18\% versus $54 \%$ ) and liver transplantation ( $2 \%$ versus $15 \%$ ) than patients who require continuous corticosteroid therapy for $\geq 36$ months to achieve these same improvements (51). Elderly patients respond more quickly than young adults, and patients $\geq 60$ years of age who do not respond within six months generate greater concern at this interval than patients $\leq 40$ years of age (51). The rapidity of the treatment response must be monitored closely; the challenge is to develop individualized management strategies that maximize the speed and degree of improvement.

\section{INCORPORATING NEW DRUGS INTO TREATMENT STRATEGIES}

Mycophenolate mofetil and budesonide are emerging as new frontline and salvage therapies for autoimmune hepatitis $(8,15)$. These drugs are unlicensed in the United States for use in autoimmune hepatitis, and their administration has been for off-label indications. The challenge is to incorporate them into safe and effective management strategies (Table 4).

Mycophenolate mofetil and budesonide are the most commonly used and reported nonstandard drugs that have been administered in autoimmune hepatitis, and are representative of an evolving treatment repertoire. Other pharmacological agents mainly used in rescue therapy include the calcineurin inhibitors (cyclosporine and tacrolimus) and rapamycin $(12,13,15,62,82)$.

\section{Mycophenolate mofetil}

Mycophenolate mofetil is a next-generation purine antagonist that has been supported as a rescue agent in autoimmune hepatitis by 11 small single-centre experiences $(8,15)$ (Table 4). A compilation of recent experiences indicates that the drug is effective in $45 \%$ of treated patients and ineffective or poorly tolerated in $55 \%$. Patients treated for azathioprine intolerance improve more commonly than patients treated for corticosteroid-refractory liver disease (58\% versus $23 \%)(8,15)$, and the optimal target population for this agent is small.

Treatment with mycophenolate mofetil has several drawbacks that must be considered (82). It is six to seven times more expensive than azathioprine; corticosteroids must be continued in most patients; treatment is indefinite; side effects occur in 3\% to 34\%; and it has 
TABLE 5

Feasible site-specific molecular and cellular interventions in autoimmune hepatitis (AIH)

\begin{tabular}{|c|c|c|}
\hline Intervention & Intervention attributes & Challenges \\
\hline \multirow[t]{2}{*}{ Monoclonal antibodies to CD3 } & Nonmitogenic $(7,12,14)$ & Untried in AlH (12) \\
\hline & Targets $T$ cell antigen receptor $(7,12,14)$ & Side effects (fever, anemia, rash, infection) \\
\hline
\end{tabular}

Promotes apoptosis, TGF- $\beta$ release and regulatory T cell function $(12,14)$

Effective in diabetic patients $(7,12,14)$

Monoclonal antibodies to CD20

Targets B lymphocytes (14)

Prevents autoantibody production and antibody-dependent cytotoxicity (14)

Limits cytokine production, antigen presentation, and T cell activation (14)

Limited trials in AlH $(14,62,89)$

Intravenous infusion required (89)

Leukoencephalopathy (14)

Interstitial pneumonitis (14)

Virus reactivation (14)

Bacterial infections (14)

$\begin{array}{ll}\text { Recombinant CTLA-4Ig } & \text { Blocks second costimulatory T cell signal }(12,14) \\ & \text { Approved for rheumatoid arthritis }(12,14) \\ & \text { Effective in animal model of primary biliary cirrhosis } \\ \text { Adoptive transfer of regulatory T cells } & \text { Modulate immune response }(12,14) \\ & \text { Generate and maintain in cell culture (94) } \\ & \text { Success in animal model of AlH (93) } \\ \text { Tailored glycolipid antigen stimulation } & \text { Customized antigenic stimulation (96) } \\ \text { of natural killer T cells } & \text { Modulate immune response (95) } \\ & \text { Effective in other immune diseases (96-98) }\end{array}$

Untried in AlH $(3,2,14)$

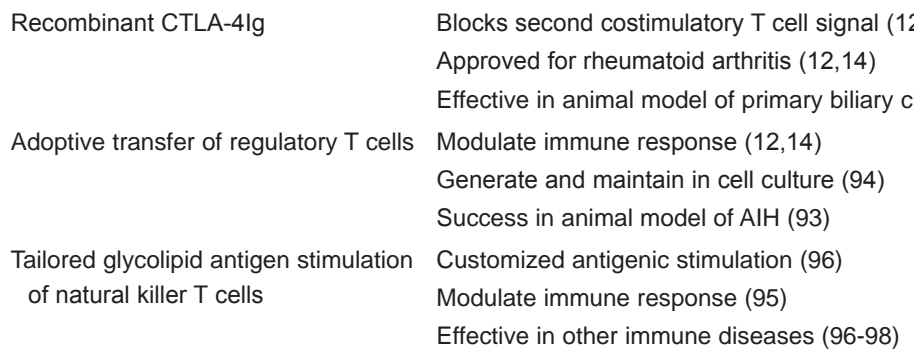

$\begin{array}{ll}\text { Recombinant CTLA-4lg } & \text { Blocks second costimulatory T cell signal }(12,14) \\ & \text { Approved for rheumatoid arthritis }(12,14) \\ & \text { Effective in animal model of primary biliary cirrhosis (90) } \\ \text { Adoptive transfer of regulatory T cells } & \text { Modulate immune response }(12,14) \\ & \text { Generate and maintain in cell culture (94) } \\ & \text { Success in animal model of AlH (93) } \\ \text { Tailored glycolipid antigen stimulation } & \text { Customized antigenic stimulation (96) } \\ \text { of natural killer T cells } & \text { Modulate immune response (95) } \\ & \text { Effective in other immune diseases (96-98) }\end{array}$

Uncertain pathogenic mechanisms (correct

T cell deficiencies or bolster effect) $(91,92)$

Untried in AlH (14)

Uncertain disease specificity (14)

Numbers in parentheses refer to references. CTLA-4Ig Cytotoxic T cell antigen-4 fused with immunoglobulin; TGF- $\beta$ Transforming growth factor-beta

been classified as a category D drug in pregnancy (82). Severe cranial, facial and cardiac abnormalities have been described in human neonates born of treated mothers (83). Although the metabolism of mycophenolate mofetil is independent of the thiopurine methyltransferase pathway, it can still induce myelosuppression (82). Consequently, it should not be used in patients whose azathioprine intolerance is reflected by cytopenia.

\section{Budesonide}

Budesonide is a next-generation glucocorticoid with $90 \%$ first-pass hepatic clearance and metabolites devoid of glucocorticoid activity (39) (Table 4). Budesonide (6 mg/day to $9 \mathrm{mg} /$ day) in combination with azathioprine (1 $\mathrm{mg} / \mathrm{kg} / \mathrm{day}$ to $2 \mathrm{mg} / \mathrm{kg} / \mathrm{day})$ normalized serum aminotransferase levels more commonly (47\% versus 18\%) and with fewer side effects ( $28 \%$ versus $53 \%$ ) than the combination regimen of prednisone $(40 \mathrm{mg} /$ day tapered to $10 \mathrm{mg} /$ day $)$ and azathioprine $(1 \mathrm{mg} / \mathrm{kg} /$ day to $2 \mathrm{mg} / \mathrm{kg} /$ day $)$ when administered as frontline therapy for six months (84). Budesonide in combination with azathioprine is emerging as an alternative frontline treatment despite uncertainties regarding the frequency of histological resolution during treatment and the durability of the response. The challenge is to characterize its appropriate target population.

Treatment with budesonide also has caveats that must be considered (Table 4). Budesonide is not effective as a salvage therapy for corticosteroid-refractory disease, nor can it be switched with prednisone without incurring severe withdrawal symptoms $(39,85)$. Concurrent immune diseases, such as vasculitis or synovitis, may exacerbate presumably because of the high first-pass hepatic clearance of the drug and its low systemic bioavailability (85). In contrast, typical corticosteroid-induced side effects can develop in patients with cirrhosis presumably because of decreased first-pass hepatic clearance of the drug and increased systemic bioavailability $(86,87)$. Budesonide therapy appears to be best suited for treatment-naive, noncirrhotic patients with uncomplicated disease.

New drugs will continue to emerge in autoimmune hepatitis as the need for them persists, their putative actions have appeal and their availability is ensured. The great challenge is to develop a collaborative network of clinical investigators that can assess these new agents in a rigorous and timely fashion.

\section{DEVELOPING SITE-SPECIFIC MOLECULAR AND CELLULAR INTERVENTIONS}

Site-specific molecular and cellular interventions are now feasible in autoimmune hepatitis mainly because of successes already achieved in other immune-mediated diseases $(3,12,14)$. These interventions include the use of monoclonal antibodies, recombinant molecules and manipulation of immune cells (Table 5). Each modality has had little or no application in autoimmune hepatitis, but its consideration as a treatment opportunity has been justified by the nature of its putative actions and its performance in other autoimmune diseases. The challenge is to establish the efficacy and safety of each modality.

Monoclonal antibodies to CD3 and CD20

Nonmitogenic monoclonal antibodies to CD3 target the T cell antigen receptor of liver-infiltrating cytotoxic $\mathrm{T}$ cells and induce their apoptosis $(7,12,14)$ (Table 5). This treatment has already been used successfully in animal models and humans with type 1 diabetes and awaits study in autoimmune hepatitis. Monoclonal antibodies to CD20 can blunt clonal expansion of activated B cells, inhibit an antibody-dependent cytopathic process and influence the activation of $\mathrm{T}$ cells $(14,88)$. Rituximab has already been used successfully in rheumatoid arthritis and isolated cases of autoimmune hepatitis $(14,89)$ and awaits formal study in autoimmune hepatitis.

\section{Recombinant molecules to CTLA-4Ig}

Recombinant cytotoxic T lymphocyte antigen-4 fused with immunoglobulin (CTLA-4Ig) blocks the second costimulatory signal essential for immunocyte activation and can blunt the immune response $(3,12,14)$ (Table 5). Abatacept is already approved for rheumatoid arthritis in the United States and Europe, and it has recently been shown to be effective in treating a murine model of experimental PBC (90). Abatacept also awaits study in autoimmune hepatitis.

Immune cell manipulations

Regulatory $\mathrm{T}$ cells and natural killer $\mathrm{T}$ (NKT) cells exert powerful inhibitory and stimulatory actions on the key cytokine pathways involved in the development of autoimmune hepatitis, and immune cell manipulation is an additional important treatment opportunity $(3,14)$ (Table 5). Discrepancies regarding the means by which the regulatory $\mathrm{T}$ cells affect the severity of autoimmune hepatitis exist because deficiencies in the function and number of these cells in some 
studies (91) have not been evident in other studies (92). Nevertheless, the adoptive transfer of regulatory $\mathrm{T}$ cells in a murine model of experimental autoimmune hepatitis has significantly improved the histological activity index of these animals (93), and this experience has strengthened the hypothesis that the adoptive transfer of fresh regulatory T cells may be beneficial (94). The adoptive transfer of regulatory $\mathrm{T}$ cells also awaits rigorous study in autoimmune hepatitis.

NKT cells can be stimulated by glycolipid antigens that have been tailored to elicit favourable cytokine responses in a disease-specific fashion (14) (Table 5). The marine sponge-derived glycosphingolipid $\alpha$-galactosylceramide modulates the immune response of NKT cells (95), and modifications of the length and structure of the acyl chain of a synthetic $\alpha$-galactosylceramide molecule can affect NKT activity and the severity of type 1 diabetes in nonobese diabetic mice (96). Structure-guided design of the triggering glycolipid antigen can customize the immune response to the individual as well as the disease. Furthermore, individualized adjustments in the duration of NKT cell stimulation will prevent excessive activity of these immune modulating cells and potentially deleterious effects while maximizing their benefit $(96,97)$. NKT cell manipulation has already been used successfully in animal models of type 1 diabetes, lupus erythematosus and collagen-induced rheumatoid arthritis, and awaits study in autoimmune hepatitis $(14,98)$.

\section{OVERVIEW}

Autoimmune hepatitis has multiple challenges in its diagnosis and management; these challenges are being met by ongoing clinical and investigational studies. Diagnosis has already been improved by recognizing the diversity of clinical phenotypes associated with autoimmune hepatitis $(4,6)$. Current treatment strategies have been improved by requiring normal liver tests and liver tissue before drug withdrawal and instituting long-term maintenance therapy after the first relapse $(7,8,49)$. Problematic patients can be identified early by scoring systems that reflect early prognosis $(70,71)$, clinical phenotypes that reflect age and genetic predisposition (72), serological markers such as anti-SLA (73), and the rapidity and completeness of the response to conventional corticosteroid treatment (51). New drugs can now be considered as a rescue agent for azathioprine intolerance or refractory liver disease (mycophenolate mofetil) $(8,15,82)$ or as a frontline therapy in noncirrhotic, treatment-naive patients with uncomplicated disease (budesonide) (84). Experiences with monoclonal antibodies (anti-CD3 and anti-CD20), recombinant molecules (recombinant CTLA-4Ig) and immune cell manipulations (regulatory T cells and NKT cells) in animal models and humans with immunemediated diseases now identify feasible interventions that may further expand the therapeutic horizon $(3,12,14)$.

These efforts to meet current diagnostic and management challenges in autoimmune hepatitis, in turn, generate new challenges that remain unaddressed. There is a need to revise current diagnostic criteria to accommodate patients with acute severe (fulminant) presentations (16) and cholestatic features (ie, overlap syndromes) (47). The efficacy and safety of current treatment regimens need to be improved by developing therapeutic ranges based on blood levels for each drug $(1,8)$. Problematic patients must be identified using biological markers (autoantibodies, cytokine levels, and immune cell counts or function) or by dynamic indexes that correlate time-related changes in disease manifestations to outcome. New interventions must continue to be identified and evaluated, and should include agents that can strengthen current regimens, such as antioxidants ( $\mathrm{N}$-acetylcysteine and S-adenosylmethionine) $(14,99,100)$, or that can rescue patients from corticosteroid-refractory disease (rapamycin, monoclonal antibodies to $\mathrm{CD} 3$ or $\mathrm{CD} 20$, abatacept, or adoptive transfer of regulatory $\mathrm{T}$ cells or NKT cells) $(3,12-14)$. Challenges exist in autoimmune hepatitis because they reflect important deficiencies in current management, and they will continue to emerge as healthy consequences of progress.

DISCLAIMER: Presented in part as the CLF-CASL Gold Medal Lecture during Canadian Digestive Diseases Week and Annual Winter Meeting of the Canadian Association for the Study of the Liver, Victoria, British Columbia, March 2, 2013.

DISCLOSURES: This review did not receive financial support from a funding agency or institution. Albert J Czaja MD has no conflict of interests to declare.

\section{REFERENCES}

1. Czaja AJ, Bianchi FB, Carpenter HA, et al. Treatment challenges and investigational opportunities in autoimmune hepatitis. Hepatology 2005;41:207-15.

2. Czaja AJ. Difficult treatment decisions in autoimmune hepatitis. World J Gastroenterol 2010;16:934-47.

3. Czaja AJ. Emerging opportunities for site-specific molecular and cellular interventions in autoimmune hepatitis. Dig Dis Sci 2010;55:2712-26.

4. Czaja AJ. Diverse manifestations and evolving treatments of autoimmune hepatitis. Minerva Gastroenterol Dietol 2005;51:313-33.

5. Czaja AJ, Bayraktar Y. Non-classical phenotypes of autoimmune hepatitis and advances in diagnosis and treatment. World J Gastroenterol 2009;15:2314-28.

6. Czaja AJ. Autoimmune hepatitis in diverse ethnic populations and geographical regions. Expert Rev Gastroenterol Hepatol 2013;7:365-85.

7. Czaja AJ, Manns MP. Advances in the diagnosis, pathogenesis and management of autoimmune hepatitis. Gastroenterology 2010;139:58-72.

8. Czaja AJ. Advances in the current treatment of autoimmune hepatitis. Dig Dis Sci 2012;57:1996-2010.

9. Czaja AJ. Autoimmune hepatitis. Part A: Pathogenesis. Expert Rev Gastroenterol Hepatol 2007;1:113-28.

10. Czaja AJ. Genetic factors affecting the occurrence, clinical phenotype, and outcome of autoimmune hepatitis. Clin Gastroenterol Hepatol 2008;6:379-88.

11. Liberal R, Longhi MS, Mieli-Vergani G, Vergani D. Pathogenesis of autoimmune hepatitis. Best Prac Res Clin Gastroenterol 2011;25:653-64.
12. Czaja AJ. Promising pharmacological, molecular and cellular treatments of autoimmune hepatitis. Curr Pharm Des 2011;17:3120-40.

13. Czaja AJ. Nonstandard drugs and feasible new interventions for autoimmune hepatitis. Part I. Inflamm Allergy Drug Targets 2012;11:337-50.

14. Czaja AJ. Nonstandard drugs and feasible new interventions for autoimmune hepatitis. Part II. Inflamm Allergy Drug Targets 2012;11:351-63.

15. Czaja AJ. Autoimmune hepatitis: Focusing on treatments other than steroids. Can J Gastroenterol 2012;26:615-20.

16. Czaja AJ. Acute and acute severe (fulminant) autoimmune hepatitis. Dig Dis Sci 2013;58:897-914.

17. Kogan J, Safadi R, Ashur Y, Shouval D, Ilan Y. Prognosis of symptomatic versus asymptomatic autoimmune hepatitis: A study of 68 patients. J Clin Gastroenterol 2002;35:75-81.

18. Feld JJ, Dinh H, Arenovich T, et al. Autoimmune hepatitis: Effect of symptoms and cirrhosis on natural history and outcome. Hepatology 2005;42:53-62.

19. Pratt DS, Fawaz KA, Rabson A, Dellelis R, Kaplan MM. A novel histological lesion in glucocorticoid-responsive chronic hepatitis. Gastroenterology 1997;113:664-8.

20. Okano N, Yamamoto K, Sakaguchi K, et al. Clinicopathological features of acute-onset autoimmune hepatitis. Hepatol Res 2003;25:263-70.

21. Kessler WR, Cummings OW, Eckert G, et al. Fulminant hepatic failure as the initial presentation of acute autoimmune hepatitis Clin Gastroenterol Hepatol 2004;2:625-31.

22. Misdraji J, Thiim M, Graeme-Cook FM. Autoimmune hepatitis with centrilobular necrosis. Am J Surg Pathol 2004;28:471-8. 
23. Miyake Y, Iwasaki Y, Terada R, et al. Clinical features of Japanese type 1 autoimmune hepatitis patients with zone III necrosis. Hepatol Res 2007;37:801-5.

24. Czaja AJ, Carpenter HA. Autoimmune hepatitis with incidental histologic features of bile duct injury. Hepatology 2001;34:659-65.

25. Czaja AJ, Muratori P, Muratori L, Carpenter HA, Bianchi FB. Diagnostic and therapeutic implications of bile duct injury in autoimmune hepatitis. Liver Int 2004;24:322-9.

26. Alvarez F, Berg PA, Bianchi FB, et al. International Autoimmune Hepatitis Group Report: Review of criteria for diagnosis of autoimmune hepatitis. J Hepatol 1999;31:929-38.

27. Hennes EM, Zeniya M, Czaja AJ, et al. Simplified criteria for the diagnosis of autoimmune hepatitis. Hepatology 2008;48:169-76.

28. Ferrari R, Pappas G, Agostinelli D, et al. Type 1 autoimmune hepatitis: Patterns of clinical presentation and differential diagnosis of the 'acute' type. QJM 2004;97:407-12.

29. Stravitz RT, Lefkowitch JH, Fontana RJ, et al. Autoimmune acute liver failure: Proposed clinical and histological criteria. Hepatology 2011;53:517-26.

30. Czaja AJ. Diagnosis, pathogenesis, and treatment of autoimmune hepatitis after liver transplantation. Dig Dis Sci 2012;57:2248-66.

31. Abe M, Hiasa Y, Masumoto T, et al. Clinical characteristics of autoimmune hepatitis with histological features of acute hepatitis. Hepatol Res 2001;21:213-9.

32. Fujiwara K, Fukuda Y, Yokosuka O. Precise histological evaluation of liver biopsy specimen is indispensable for diagnosis and treatment of acute-onset autoimmune hepatitis. J Gastroenterol 2008;43:951-8.

33. Miyake Y, Iwasaki Y, Kobashi H, et al. Autoimmune hepatitis with acute presentation in Japan. Dig Liver Dis 2010;42:51-4.

34. Yasui S, Fujiwara K, Yonemitsu Y, et al. Clinicopathological features of severe and fulminant forms of autoimmune hepatitis. J Gastroenterol 2011;46:378-90.

35. Abe M, Onji M, Kawai-Ninomiya K, et al. Clinicopathologic features of the severe form of acute type 1 autoimmune hepatitis. Clin Gastroenterol Hepatol 2007;5:255-8.

36. Ichai P, Duclos-Vallee JC, Guettier C, et al. Usefulness of corticosteroids for the treatment of severe and fulminant forms of autoimmune hepatitis. Liver Transpl 2007;13:996-1003.

37. Czaja AJ, Rakela J, Ludwig J. Features reflective of early prognosis in corticosteroid-treated severe autoimmune chronic active hepatitis. Gastroenterology 1988;95:448-53.

38. Czock D, Keller F, Rasche FM, Haussler U. Pharmacokinetics and pharmacodynamics of systemically administered glucocorticoids. Clin Pharmacokinet 2005;44:61-98.

39. Czaja AJ. Drug choices in autoimmune hepatitis: Part A - steroids. Expert Rev Gastroenterol Hepatol 2012;6:603-15.

40. Takikawa Y, Suzuki K. Clinical epidemiology of fulminant hepatitis in Japan. Hepatol Res 2008;38(Suppl 1):S14-8.

41. Nunez-Martinez O, De la Cruz G, Salcedo M, et al. Liver transplantation for autoimmune hepatitis: Fulminant versus chronic hepatitis presentation. Transplant Proc 2003;35:1857-8.

42. Czaja AJ. Corticosteroids or not in severe acute or fulminant autoimmune hepatitis: Therapeutic brinksmanship and the point beyond salvation. Liver Transpl 2007;13:953-5.

43. Czaja AJ. Features and consequences of untreated type 1 autoimmune hepatitis. Liver Int 2009;29:816-23.

44. Ludwig J, Czaja AJ, Dickson ER, LaRusso NF, Wiesner RH. Manifestations of nonsuppurative cholangitis in chronic hepatobiliary diseases: Morphologic spectrum, clinical correlations and terminology. Liver 1984:4:105-16.

45. Czaja AJ, Carpenter HA, Santrach PJ, Moore SB. Autoimmune cholangitis within the spectrum of autoimmune liver disease. Hepatology 2000;31:1231-8.

46. Czaja AJ, Carpenter HA. Sensitivity, specificity, and predictability of biopsy interpretations in chronic hepatitis. Gastroenterology 1993;105:1824-32.

47. Czaja AJ. The overlap syndromes of autoimmune hepatitis. Dig Dis Sci 2013;58:326-43.

48. Boberg KM, Chapman RW, Hirschfield GM, et al. Overlap syndromes: the International Autoimmune Hepatitis Group (IAIHG) position statement on a controversial issue. J Hepatol 2011;54:374-85.

49. Manns MP, Czaja AJ, Gorham JD, et al. Practice Guidelines of the American Association for the Study of Liver Diseases. Diagnosis and management of autoimmune hepatitis. Hepatology 2010;51:2193-213.
50. Kanzler S, Gerken G, Lohr H, et al. Duration of immunosuppressive therapy in autoimmune hepatitis. J Hepatol 2001;34:354-5.

51. Czaja AJ. Rapidity of treatment response and outcome in type 1 autoimmune hepatitis. J Hepatol 2009;51:161-7.

52. Czaja AJ, Carpenter HA. Decreased fibrosis during corticosteroid therapy of autoimmune hepatitis. J Hepatol 2004;40:646-52.

53. Roberts SK, Therneau TM, Czaja AJ. Prognosis of histological cirrhosis in type 1 autoimmune hepatitis. Gastroenterology 1996;110:848-57.

54. Kanzler S, Lohr H, Gerken G, Galle PR, Lohse AW. Long-term management and prognosis of autoimmune hepatitis (AIH): A single center experience. Z Gastroenterol 2001;39:339-41, 44-8.

55. Floreani A, Niro G, Rosa Rizzotto E, et al. Type I autoimmune hepatitis: Clinical course and outcome in an Italian multicentre study. Aliment Pharmacol Ther 2006;24:1051-7.

56. Seo S, Toutounjian R, Conrad A, Blatt L, Tong MJ. Favorable outcomes of autoimmune hepatitis in a community clinic setting. J Gastroenterol Hepatol 2008;23:1410-4.

57. Hoeroldt B, McFarlane E, Dube A, et al. Long-term outcomes of patients with autoimmune hepatitis managed at a nontransplant center. Gastroenterology 2011;140:1980-9.

58. Verma S, Gunuwan B, Mendler M, Govindrajan S, Redeker A. Factors predicting relapse and poor outcome in type I autoimmune hepatitis: Role of cirrhosis development, patterns of transaminases during remission and plasma cell activity in the liver biopsy. Am J Gastroenterol 2004;99:1510-6.

59. Miyake Y, Iwasaki Y, Terada R, et al. Persistent normalization of serum alanine aminotransferase levels improves the prognosis of type 1 autoimmune hepatitis. J Hepatol 2005;43:951-7.

60. Montano-Loza AJ, Carpenter HA, Czaja AJ. Improving the end point of corticosteroid therapy in type 1 autoimmune hepatitis to reduce the frequency of relapse. Am J Gastroenterol 2007;102:1005-12.

61. Luth S, Herkel J, Kanzler S, et al. Serologic markers compared with liver biopsy for monitoring disease activity in autoimmune hepatitis. J Clin Gastroenterol 2008;42:926-30.

62. Selvarajah V, Montano-Loza AJ, Czaja AJ. Systematic review: Managing suboptimal treatment responses in autoimmune hepatitis with conventional and nonstandard drugs. Aliment Pharmacol Ther 2012;36:691-707.

63. Czaja AJ, Menon KV, Carpenter HA. Sustained remission after corticosteroid therapy for type 1 autoimmune hepatitis: A retrospective analysis. Hepatology 2002;35:890-7.

64. Johnson PJ, McFarlane IG, Williams R. Azathioprine for long-term maintenance of remission in autoimmune hepatitis. N Engl J Med 1995;333:958-63.

65. Czaja AJ. Low-dose corticosteroid therapy after multiple relapses of severe HBsAg-negative chronic active hepatitis. Hepatology 1990;11:1044-9.

66. Seela S, Sheela H, Boyer JL. Autoimmune hepatitis type 1: Safety and efficacy of prolonged medical therapy. Liver Int 2005;25:734-9.

67. van Gerven NM, Verwer BJ, Witte BI, et al. Relapse is almost universal after withdrawal of immunosuppressive medication in patients with autoimmune hepatitis in remission. J Hepatol 2013;58:141-7.

68. Czaja AJ, Davis GL, Ludwig J, Taswell HF. Complete resolution of inflammatory activity following corticosteroid treatment of $\mathrm{HBsAg}$ negative chronic active hepatitis. Hepatology 1984;4:622-7.

69. Montano-Loza AJ, Carpenter HA, Czaja AJ. Consequences of treatment withdrawal in type 1 autoimmune hepatitis. Liver Int 2007;27:507-15.

70. Montano-Loza AJ, Carpenter HA, Czaja AJ. Features associated with treatment failure in type 1 autoimmune hepatitis and predictive value of the Model of End-stage Liver Disease. Hepatology 2007;46:1138-45.

71. Yeoman AD, Westbrook RH, Zen Y, et al. Early predictors of corticosteroid treatment failure in icteric presentations of autoimmune hepatitis. Hepatology 2011;53:926-34.

72. Czaja AJ, Carpenter HA. Distinctive clinical phenotype and treatment outcome of type 1 autoimmune hepatitis in the elderly. Hepatology 2006;43:532-8.

73. Czaja AJ. Autoantibodies as prognostic markers in autoimmune liver disease. Dig Dis Sci 2010;55:2144-61.

74. Montano-Loza AJ, Shums Z, Norman GL, Czaja AJ. Prognostic implications of antibodies to Ro/SSA and soluble liver antigen in type 1 autoimmune hepatitis. Liver Int 2012;32:85-92. 
75. Czaja AJ, Strettell MD, Thomson LJ, et al. Associations between alleles of the major histocompatibility complex and type 1 autoimmune hepatitis. Hepatology 1997;25:317-23.

76. Czaja AJ, Donaldson PT, Lohse AW. Antibodies to soluble liver antigen/liver pancreas and HLA risk factors for type 1 autoimmune hepatitis. Am J Gastroenterol 2002;97:413-9.

77. Efe C, Ozaslan E, Wahlin S, et al. Antibodies to soluble liver antigen in patients with various liver diseases: A multicentre study. Liver Int 2013;33:190-6.

78. Ma Y, Okamoto M, Thomas MG, et al. Antibodies to conformational epitopes of soluble liver antigen define a severe form of autoimmune liver disease. Hepatology 2002;35:658-64.

79. Baeres M, Herkel J, Czaja AJ, et al. Establishment of standardised SLA/LP immunoassays: Specificity for autoimmune hepatitis, worldwide occurrence, and clinical characteristics. Gut 2002;51:259-64.

80. Otey CA, Carpen O. Alpha-actinin revisited: A fresh look at an old player. Cell Motil Cytoskeleton 2004;58:104-11.

81. Gueguen P, Dalekos G, Nousbaum JB, et al. Double reactivity against actin and alpha-actinin defines a severe form of autoimmune hepatitis type 1. J Clin Immunol 2006;26:495-505.

82. Czaja AJ. Drug choices in autoimmune hepatitis: Part B nonsteroids. Expert Rev Gastroenterol Hepatol 2012;6:617-35.

83. Perez-Aytes A, Ledo A, Boso V, et al. In utero exposure to mycophenolate mofetil: A characteristic phenotype? Am J Med Genet A 2008;146A:1-7.

84. Manns MP, Woynarowski M, Kreisel W, et al. Budesonide induces remission more effectively than prednisone in a controlled trial of patients with autoimmune hepatitis. Gastroenterology 2010;139:1198-206.

85. Czaja AJ, Lindor KD. Failure of budesonide in a pilot study of treatment-dependent autoimmune hepatitis. Gastroenterology 2000;119:1312-6.

86. Geier A, Gartung C, Dietrich CG, et al. Side effects of budesonide in liver cirrhosis due to chronic autoimmune hepatitis: Influence of hepatic metabolism versus portosystemic shunts on a patient complicated with HCC. World J Gastroenterol 2003;9:2681-5.

87. Snider KR, Potter TG. Budesonide for the treatment of autoimmune hepatitis. Ann Pharmacother 2011;45:1144-50.

88. Stasi R. Rituximab in autoimmune hematologic diseases: Not just a matter of B cells. Semin Hematol 2010;47:170-9.
89. Burak KW, Swain MG, Santodomino-Garzon T, et al. Rituximab for the treatment of patients with autoimmune hepatitis who are refractory or intolerant to standard therapy. Can J Gastroenterol 2013;27:273-80.

90. Dhirapong A, Yang GX, Nadler S, et al. Therapeutic effect of cytotoxic $\mathrm{T}$ lymphocyte antigen $4 /$ immunoglobulin on a murine model of primary biliary cirrhosis. Hepatology 2013;57:708-15.

91. Longhi MS, Ma Y, Bogdanos DP, et al. Impairment of CD4(+) CD25(+) regulatory T-cells in autoimmune liver disease. J Hepatol 2004:41:31-7.

92. Peiseler M, Sebode M, Franke B, et al. FOXP3 + regulatory T cells in autoimmune hepatitis are fully functional and not reduced in frequency. J Hepatol 2012;57:125-32.

93. Lapierre P, Beland K, Yang R, Alvarez F. Adoptive transfer of ex vivo expanded regulatory $\mathrm{T}$ cells in an autoimmune hepatitis murine model restores peripheral tolerance. Hepatology 2013;57:217-27.

94. Longhi MS, Meda F, Wang P, et al. Expansion and de novo generation of potentially therapeutic regulatory $\mathrm{T}$ cells in patients with autoimmune hepatitis. Hepatology 2008;47:581-91.

95. Wu L, Van Kaer L. Natural killer T cells in health and disease. Front Biosci (Schol Ed) 2011;3:236-51.

96. Blumenfeld HJ, Tohn R, Haeryfar SM, et al. Structure-guided design of an invariant natural killer T cell agonist for optimum protection from type 1 diabetes in non-obese diabetic mice. Clin Exp Immunol 2011;166:121-33.

97. Yang JQ, Kim PJ, Singh RR. Brief treatment with iNKT cell ligand alpha-galactosylceramide confers a long-term protection against lupus. J Clin Immunol 2012;32:106-13.

98. Yoshiga Y, Goto D, Segawa S, et al. Activation of natural killer T cells by alpha-carba-GalCer (RCAI-56), a novel synthetic glycolipid ligand, suppresses murine collagen-induced arthritis. Clin Exp Immunol 2011;164:236-47.

99. Majano PL, Garcia-Monzon C, Garcia-Trevijano ER, et al. S-Adenosylmethionine modulates inducible nitric oxide synthase gene expression in rat liver and isolated hepatocytes. J Hepatol 2001;35:692-9.

100. Mato JM, Camara J, Fernandez de Paz J, et al. S-adenosylmethionine in alcoholic liver cirrhosis: A randomized, placebo-controlled, double-blind, multicenter clinical trial. J Hepatol 1999;30:1081-9. 


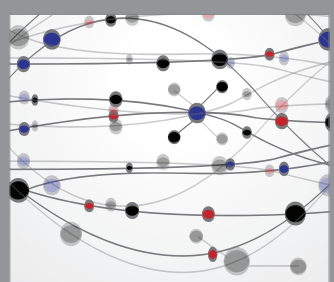

The Scientific World Journal
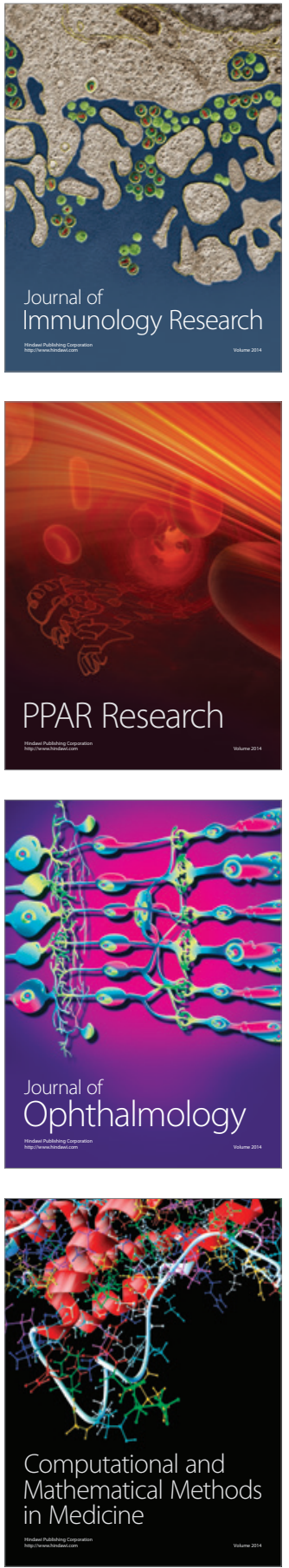

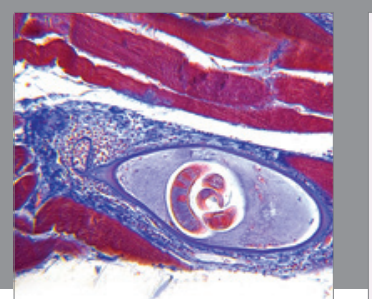

Gastroenterology Research and Practice

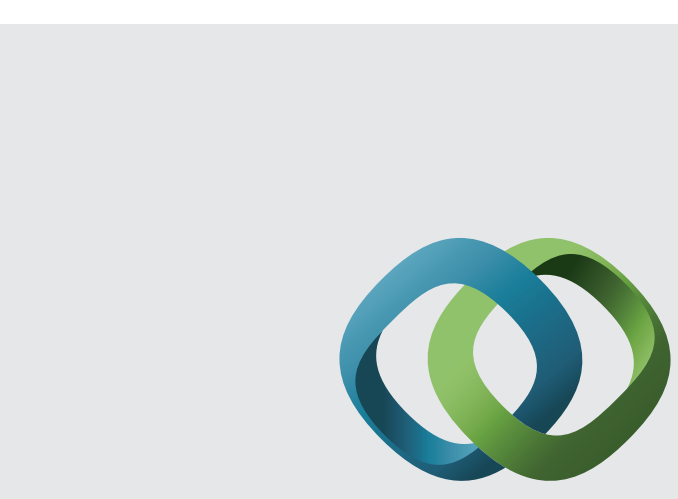

\section{Hindawi}

Submit your manuscripts at

http://www.hindawi.com
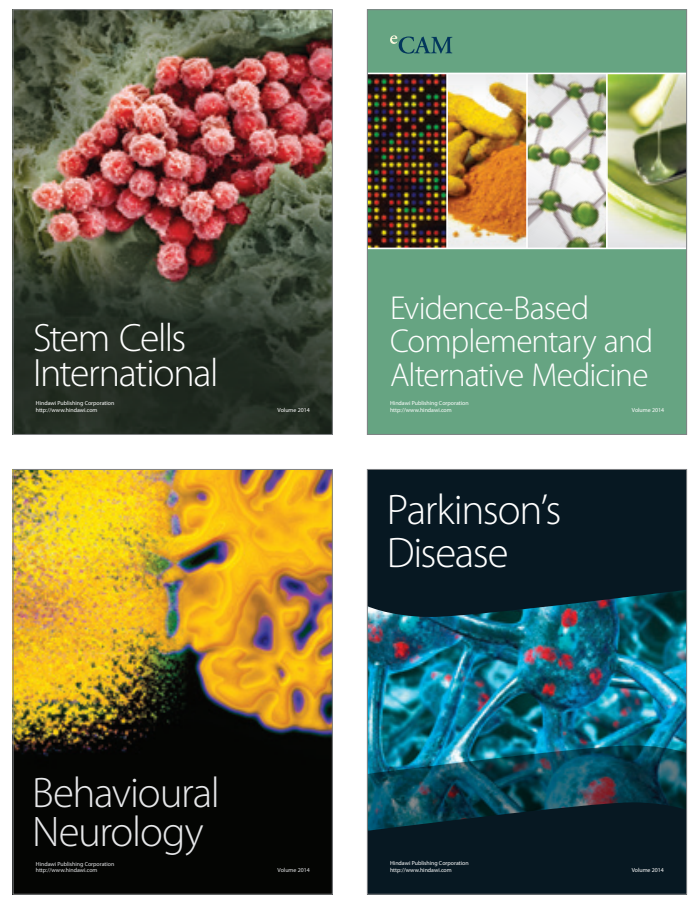
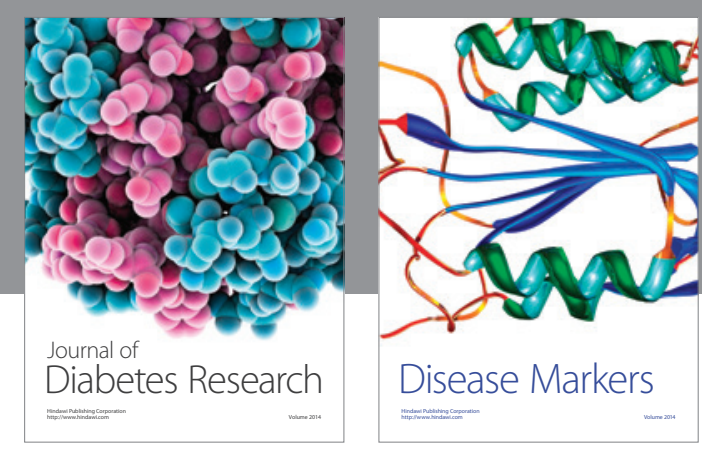

Disease Markers
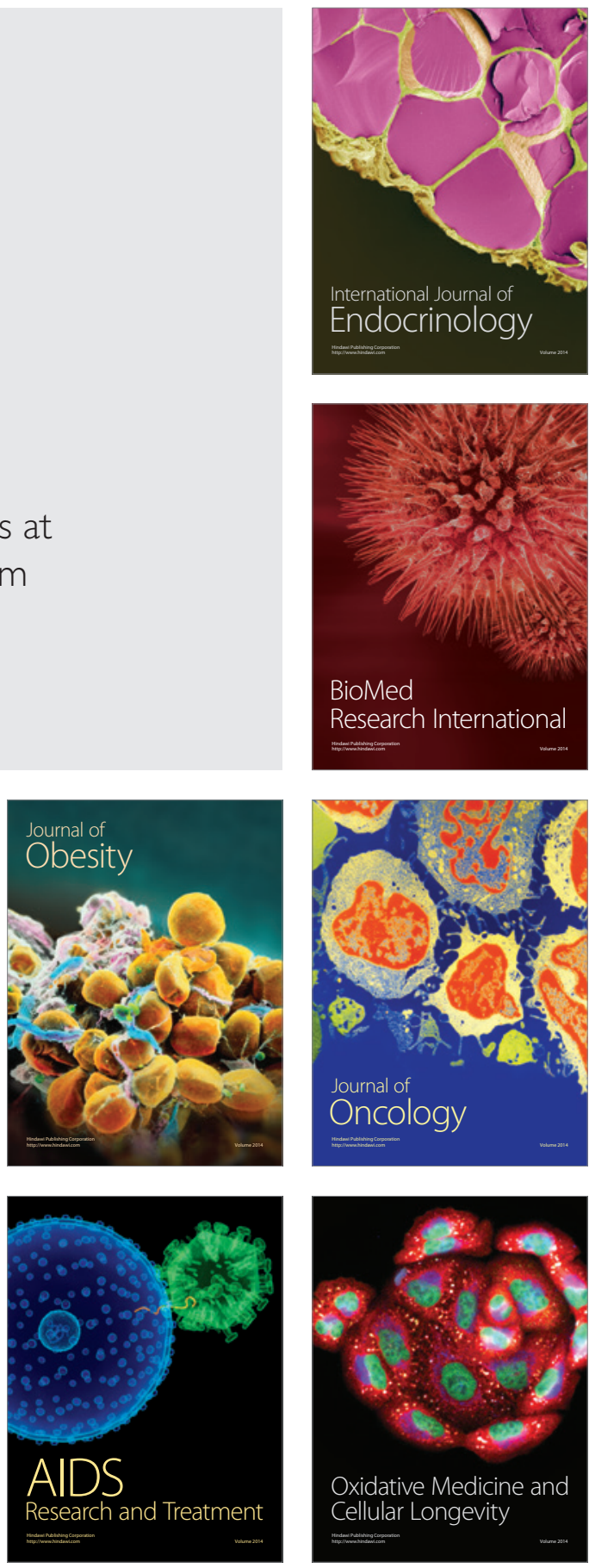